\title{
Determination of Bromine, Fluorine and Iodine in Mineral Supplements using Pyrohydrolysis for Sample Preparation
}

\author{
Ticiane Taflik, ${ }^{a}$ Fábio A. Duarte, ${ }^{b}$ Éder L. M. Flores, ${ }^{c}$ Fabiane G. Antes, ${ }^{a}$ \\ José N. G. Paniz, ${ }^{a}$ Érico M. M. Flores ${ }^{a}$ and Valderi L. Dressler ${ }^{*, a}$ \\ a Departamento de Química, Universidade Federal de Santa Maria, \\ 97105-900 Santa Maria-RS, Brazil \\ ${ }^{b}$ Escola de Química e Alimentos, Universidade Federal do Rio Grande, \\ 96203-900 Rio Grande-RS, Brazil \\ ${ }^{c}$ Coordenação de Engenharia de Alimentos, Universidade Tecnológica Federal do Paraná, \\ 85884-000 Medianeira-PR, Brazil
}

Neste trabalho foi utilizada a piroidrólise para a decomposição de suplemento mineral utilizado na nutrição animal, para a posterior determinação de F, Br e I. Flúor foi determinado por potenciometria utilizando eletrodo íon-seletivo para fluoreto, enquanto que $\mathrm{Br}$ e I foram determinados por espectrometria de massa com plasma indutivamente acoplado. Os principais parâmetros que influenciam a piroidrólise foram investigados e, após a devida avaliação dos mesmos, foram fixadas as seguintes condições: a temperatura do reator em $1000{ }^{\circ} \mathrm{C}$ durante 10 min; a proporção entre a massa de amostra e a massa de acelerador em $1+5$ e a vazão do gás carreador em $200 \mathrm{~mL} \mathrm{~min}^{-1}$. A exatidão do método foi avaliada usando teste de recuperação do analito e análise de materiais de referência certificados de rocha fosfática e de solo. O método foi aplicado para análise de suplemento mineral. Os limites de quantificação foram de 16, 0,3 e $0,07 \mu \mathrm{g} \mathrm{g}^{-1}$ para F, Br e I, respectivamente. Assim, usando-se um método relativamente simples e de baixo custo é possível a decomposição de até 5 amostras por hora. Portanto, a piroidrólise pode ser usada como um método de rotina para o preparo de amostra de suplemento mineral para a determinação de $\mathrm{F}, \mathrm{Br}$ e I.

Pyrohydrolysis was employed for mineral supplements decomposition prior to $\mathrm{F}, \mathrm{Br}$ and I determination. Fluoride determination was carried out by potentiometry using a fluoride-ion selective electrode, whereas $\mathrm{Br}$ and I were determined by inductively coupled plasma mass spectrometry. The main parameters that influence on pyrohydrolysis were investigated. After evaluation, the following conditions were established: reactor temperature of $1000{ }^{\circ} \mathrm{C}$ during $10 \mathrm{~min}$; sample plus accelerator mass ratio of $1+5$ and carrier gas (air) flow rate of $200 \mathrm{~mL} \mathrm{~min}$ ${ }^{1}$. The accuracy of the proposed method was evaluated by analyte recovery tests and analysis of certified reference materials of phosphate rock and soil. Commercial mineral supplement samples were analyzed. The limits of quantification were $16,0.3$ and $0.07 \mu \mathrm{g} \mathrm{g}^{-1}$ for $\mathrm{F}, \mathrm{Br}$ and I, respectively. By using a relatively simple and low cost pyrohydrolysis system up to 5 samples can be processed per hour. The developed sample preparation procedure can be routinely employed for $\mathrm{F}, \mathrm{Br}$ and I determination in mineral supplements.

Keywords: pyrohydrolysis, halogens determination, mineral supplement

\section{Introduction}

Several elements are essential for animals growing and breeding. Those elements required in high amounts are called macronutrients $(\mathrm{Ca}, \mathrm{Cl}, \mathrm{K}, \mathrm{P}, \mathrm{Mg}, \mathrm{Na}$, and $\mathrm{S})$ and those elements required in low concentrations are

*e-mail: valdres@quimica.ufsm.br called micronutrients $(\mathrm{Co}, \mathrm{Cu}, \mathrm{Fe}, \mathrm{I}, \mathrm{Mn}, \mathrm{Mo}, \mathrm{Se}, \mathrm{Zn}$, and eventually $\mathrm{Cr}$ and $\mathrm{F}$ are included in this group). ${ }^{1}$ The main functions of essential elements in the organism are associated to the structural composition of body and enzymatic and hormonal processes.

Although F usually increases the strength of bones and teeth, this element is generally not considered as essential. ${ }^{1}$ Fluorine is usually present as a contaminant since it is 
naturally found in phosphate rocks used in animal feed. ${ }^{2}$ Fluorine has an ambiguous effect on the animal health; while at low concentrations it prevents dental caries, at high concentration it can damage bones and even the teeth. Minor morphologic lesions were observed in young cattle receiving $20 \mathrm{mg} \mathrm{kg}^{-1} \mathrm{~F}$ per day. The maximum tolerable $\mathrm{F}$ content was set to $40 \mathrm{mg} \mathrm{kg}^{-1}$. Bromine is a non-essential element that is usually toxic to animals. The exposure to relatively high doses of Br may lead to liver and kidney injury within a short period. Low coordination and growth decrease of hepatic function and damages on intestine can be observed if animals are exposed to bromine compounds. Besides, bromine can be converted into bromide, which attacks the central nervous system when concentrations higher than 1 to $2 \mathrm{~g} \mathrm{day}^{-1}$ are ingested. ${ }^{3}$ On the other hand, iodine is an essential element for several animals, mainly for the synthesis of the thyroid hormones (thyroxine and triiodothyronine) that regulate metabolism. Because iodine is naturally found at low concentrations, the element supplementation is recommended ( 0.4 to $1.3 \mathrm{mg} \mathrm{day}^{-1}$, the maximum is $\left.10 \mathrm{mg} \mathrm{day}^{-1}\right) .{ }^{4}$ Deleterious effect caused by iodine has been reported in dairy cows that received $50 \mathrm{mg}$ of iodine per day. ${ }^{5}$ Therefore, taking into account the adverse effects caused by $\mathrm{Br}, \mathrm{F}$, and I in animals, the concentration of these elements in mineral supplements have to be controlled.

Techniques such as spectrophotometry, ${ }^{6}$ potentiometry using ion-selective electrode (ISE), ${ }^{7}$ ion chromatography, ${ }^{8,9}$ inductively coupled plasma optical emission spectrometry (ICP OES $),{ }^{10,11}$ and inductively coupled plasma mass spectrometry (ICP-MS) $)^{12-15}$ can be employed for $\mathrm{Br}$, I and $\mathrm{F}$ determination. Fluorine can also be determined by graphite furnace molecular absorption spectrometry, ${ }^{16}$ ion chromatography ${ }^{10,17}$ and capillary electrophoresis. ${ }^{18}$ It is worth citing that ICP-MS is a powerful technique for halogens determination (except for fluorine) due to the high sensitivity observed. ${ }^{19}$ However, the high salt content in mineral supplements used for animal nutrition causes serious interferences and, therefore, matrix separation is necessary. ${ }^{20,21}$

Sample preparation is usually the bottleneck in halogen determination by ICP-MS, due to memory effects caused by high volatility of halogens in acidic solutions. ${ }^{22-24}$ Therefore, alkaline fusion, ${ }^{20}$ dilution or dispersion in alkaline solution, distillation (for fluorine), combustion in bombs, ${ }^{25}$ microwave-induced combustion (MIC) ${ }^{9,26-29}$ and pyrohydrolysis ${ }^{7,17,30-32}$ are used for sample preparation.

Pyrohydrolysis is a simple alternative for decomposition of organic ${ }^{7,19,31,33}$ and inorganic ${ }^{34-36}$ materials when halogens determination is intended. The main advantages are the possibility of matrix separation and the use of a diluted alkaline solution for analytes absorbing. Application of pyrohydrolysis for analytical purposes was first investigated by Warf et al. ${ }^{37}$ In their experiment, water steam passed over a heated sample in a platinum assembly furnace was used. Volatile $\mathrm{Cl}$ and $\mathrm{F}$ species formed during pyrohydrolysis reaction were condensed and further determined by titration. The pyrohydrolysis reaction can be accelerated in presence of $\mathrm{U}, \mathrm{V}, \mathrm{Al}$, and $\mathrm{W}$ oxides. The volatile halogen species evolved can be simply condensed ${ }^{33,37}$ or collected in alkaline solutions such as $\mathrm{Na}_{2} \mathrm{CO}_{3}, \mathrm{Na}_{2} \mathrm{CO}_{3} / \mathrm{NaHCO}_{3}$ and $\left(\mathrm{NH}_{4}\right)_{2} \mathrm{CO}_{3} \cdot{ }^{24,31}$

The purpose of the present work was to develop a method for $\mathrm{F}, \mathrm{Br}$ and I determination in mineral supplements using pyrohydrolysis for sample preparation. Pyrohydrolysis was investigated in view of the difficulties associated with $\mathrm{F}, \mathrm{Br}$ and I determination in such complex matrix. The main features of the proposed method are the simplicity of sample preparation, low analyte losses and the relatively high sensitivity and sample throughput of ICP-MS for Br and I determination. Fluorine determination was performed by potentiometry because this element cannot be measured by ICP-MS.

\section{Experimental}

\section{Pyrohydrolysis apparatus}

The pyrohydrolysis apparatus employed is described elsewhere, ${ }^{7,33}$ excepting the collector flask. In the present work two flasks were used and connected by a polytetrafluoroethylene (PTFE) tube. The pyrohydrolysis apparatus employed is shown in Figure 1.

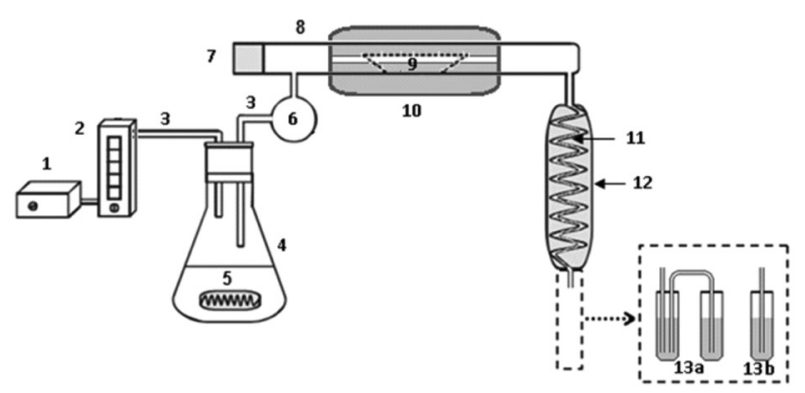

Figure 1. Pyrohydrolysis apparatus used for preparation of mineral supplement samples prior to $\mathrm{F}, \mathrm{Br}$ and I determination. 1) air pump; 2) flow meter (0.1 to $\left.1.0 \mathrm{~L} \mathrm{~min}^{-1}\right)$; 3) PTFE tubes (i.d. $=5 \mathrm{~mm}$ ); 4) $500 \mathrm{~mL}$ Erlenmeyer flask containing water; 5) heating element; 6) water trap; 7) silicone rubber; 8) quartz tube ( $\mathrm{L}=15 \mathrm{~cm}$, i.d. $=2 \mathrm{~cm})$; 9) quartz boat $(\mathrm{L}=2 \mathrm{~cm}$, width $=1 \mathrm{~cm}$, depth $=0.5 \mathrm{~cm}) ; 10)$ electrothermal furnace; 11) condenser (PTFE tube, $\mathrm{L}=50 \mathrm{~cm}$, i.d. $=0.2 \mathrm{~cm}$ ); 12) ice bath ( $1 \mathrm{~L}$ flask, filled up with ice and water); 13a) two graduated (15 $\mathrm{mL}$ ) polypropylene collector vials containing absorbing solution; $13 \mathrm{~b})$ graduated $(15 \mathrm{~mL})$ polypropylene collector vial.

Briefly, the system (Figure 1) consists of a water vapour generator unit, an electrothermal furnace, a quartz tube used 
as reactor where a quartz holder for the sample is placed, a vapour condenser and a collector (one or two flasks) of the products from the pyrohydrolysis reaction. All parts of the system were interconnected with PTFE tubes. An air pump is used in order to force the water vapour through the reactor. The water trap, which is made of glass, avoids the introduction of water drops into the reactor. The condensed solution is collected separately: for $\mathrm{F}$ determination the vapour can be simply condensed using one flask, while for $\mathrm{Br}$ and I determination the vapour is condensed and trapped in an alkaline medium in two collection flasks connected in series. The determination of $\mathrm{Br}, \mathrm{F}$ and I was carried out directly in the collected solution, with or without dilution.

\section{Instrumentation}

Bromide and I were determined using an inductively coupled plasma mass spectrometer (Perkin-Elmer-SCIEX, model Elan DRC II, Thornhill, Canada) equipped with a concentric nebulizer (Meinhard Associates, Golden, CO), a cyclonic spray chamber (Glass Expansion, Inc., West Melbourne, Australia), and a quartz torch with a quartz injector tube (2 $\mathrm{mm}$ i.d.). Instrumental performance optimization, including nebulizer gas flow rate and ion lens voltage, was performed following the instructions of the instrument manufacturer. Plasma was operated at $1300 \mathrm{~W}$, while the flow rates of plasma gas, auxiliary gas, and nebulizer gas were 15.0, 1.20, and 1.15 $\mathrm{L} \mathrm{min}^{-1}$, respectively. Argon of $99.996 \%$ purity (White MartinsPraxair, São Paulo, Brazil) was used. The monitored isotopes were ${ }^{79} \mathrm{Br},{ }^{81} \mathrm{Br}$, and ${ }^{129} \mathrm{I}$.

Fluoride was determined using a potentiometer (model $781 \mathrm{pH} /$ ion meter, Metrohm, Herisau, Switzerland) equipped with a fluoride ISE (model 6.0502.150, Metrohm). The method used for F determination is described elsewhere. ${ }^{33}$

\section{Reagents}

All chemicals used were of analytical grade. Solutions were prepared using distilled/deionised water previously purified in a Milli-Q system (18.2 $\mathrm{M} \Omega \mathrm{cm}$, Millipore, Billerica, MA, USA). Nitric acid $(65 \% \mathrm{~m} / \mathrm{m})$ from Merck (Darmstadt, Germany) was doubly distillated in a quartz still (model duoPUR 2.01E, Milestone, Sorisole, Italy). A $10 \%$ (v/v) solution of this acid was used for vessel cleaning.

Vanadium pentoxide $\left(\mathrm{V}_{2} \mathrm{O}_{5}\right)$ used as accelerator was obtained by heating ammonium vanadate $\left(\mathrm{NH}_{4} \mathrm{VO}_{3}\right.$ from Merck) in a platinum crucible during $4 \mathrm{~h}$ at $550{ }^{\circ} \mathrm{C} .{ }^{7}$

Total ionic strength adjustment buffer (TISAB) was prepared by mixing $58 \mathrm{~g}$ of sodium chloride (Merck), $4 \mathrm{~g}$ of 1,2-cyclohexilenediaminetetraacetic acid (Merck) and $57 \mathrm{~mL}$ of acetic acid (Merck) in $500 \mathrm{~mL}$ of water. The $\mathrm{pH}$ of this solution was adjusted to 5.5 with a $10 \%(\mathrm{~m} / \mathrm{v})$ sodium hydroxide (Merck) solution. Then, the volume of the solution was completed to $1000 \mathrm{~mL}$ with water.

A stock solution of sodium carbonate/sodium bicarbonate was prepared by dissolution of $10.6 \mathrm{~g}$ of $\mathrm{Na}_{2} \mathrm{CO}_{3}$ (Merck) and $10.6 \mathrm{~g} \mathrm{NaHCO}$ (Merck) in water and the volume completed to $1000 \mathrm{~mL}$. Tetramethylammonium hydroxide (25\% v/v from Sigma-Aldrich,) and $25 \%$ (v/v) ammonium hydroxide (Merck) were also evaluated to be used as absorbing solution for $\mathrm{Br}$ and I. All alkaline solutions were diluted as necessary for analyte collection or preparation of calibration solutions.

A $1000 \mathrm{mg} \mathrm{L}^{-1} \mathrm{~F}^{-}$solution was prepared in water (by dilution of a Titrisol-Merck solution). Fluoride calibration solutions ranging from 0.25 to $10.0 \mathrm{mg} \mathrm{L}^{-1}$ were prepared in water, by serial dilutions of the $1000 \mathrm{mg} \mathrm{L}^{-1} \mathrm{~F}^{-}$stock solution. In order to obtain the $\mathrm{F}^{-}$calibration curve, equal volumes of each calibration solution and TISAB were mixed. Stock solutions containing $1000 \mathrm{mg} \mathrm{L}^{-1}$ of $\mathrm{Br}^{-}$and $\mathrm{I}^{-}$were obtained from $\mathrm{KBr}$ (Merck) and $\mathrm{KI}$ (Merck), respectively. Calibration solutions of $\mathrm{Br}^{-}$and $\mathrm{I}^{-}$were prepared by serial dilution of the stock solution in $\left(\mathrm{NH}_{4}\right)_{2} \mathrm{CO}_{3} / \mathrm{NH}_{4} \mathrm{HCO}_{3} 50 \mathrm{mmol} \mathrm{L} \mathrm{m}^{-1}$. The calibration solutions were in the range of 1.0 to $20 \mathrm{mg} \mathrm{L}^{-1}$ for $\mathrm{Br}$ and 0.1 to $20 \mu \mathrm{g} \mathrm{L} \mathrm{L}^{-1}$ for $\mathrm{I}$.

\section{Samples}

Four samples of mineral supplements (named as A, B, C, and D) were obtained in local market. Prior being submitted to pyrohydrolysis, all samples were ground in an agate mortar in order to obtain particle sizes lower than $100 \mu \mathrm{m}$. A certified sample of phosphate rock (IPT-18) from Instituto de Pesquisas Tecnológicas (IPT), São Paulo, Brazil, and a certified soil (Montana Soil SRM 2711) from the National Institute of Standards and Technology (NIST, Gaithersburg, MD, USA) were used for accuracy evaluation.

\section{Procedures}

Aliquots of sample in the range of 30 to $150 \mathrm{mg}$ and up to $450 \mathrm{mg}$ of $\mathrm{V}_{2} \mathrm{O}_{5}$ were weighed in quartz holders. Sample A was used for method development. The temperature of the reactor was gradually increased (during $5 \mathrm{~min}$ ) up to the maximum temperature and hold during $10 \mathrm{~min}$ at each selected temperature. The reactor temperature was measured using a thermocouple. Humidified air was passed through the quartz reactor at a flow rate ranging from 
100 to $600 \mathrm{~mL} \mathrm{~min}^{-1}$. For $\mathrm{Br}$ and I collection, a solution containing $\mathrm{Na}_{2} \mathrm{CO}_{3}$ and $\mathrm{NaHCO}_{3}$ with concentration ranging from 0 to $50 \mathrm{mmol} \mathrm{L}^{-1}$ was used. In this case, it was necessary to use two flasks containing absorbing solution (Figure 1(13a)); one with $5 \mathrm{~mL}$ and the other with $3 \mathrm{~mL}$. After pyrohydrolysis reaction, the solutions collected in both flasks were mixed and the volume was completed to $15 \mathrm{~mL}$ using ultrapure water. For F determination, about $8 \mathrm{~mL}$ of water vapour were collected and the volume was completed to $10 \mathrm{~mL}$ using ultrapure water. An aliquot of $10 \mathrm{~mL}$ of TISAB was mixed with this solution before $\mathrm{F}$ determination. A blank sample was obtained by submitting the sample holder containing $\mathrm{V}_{2} \mathrm{O}_{5}$ to the same conditions used for the samples. All flasks used were thoroughly washed with $10 \%$ (v/v) $\mathrm{HNO}_{3}$ and water prior use. Recovery tests were carried out by spiking $\mathrm{Br}^{-}, \mathrm{F}^{-}$and $\mathrm{I}^{-}$to $50 \mathrm{mg}$ of samples A, B, C, and D.

Statistical analysis, including one-way analysis of variance (ANOVA), was performed using GraphPad InStat (GraphPad InStat Software Inc., Version 3.00, 1997) software. A significance level of $95 \%$ was used.

\section{Results and Discussion}

The influences of alkaline solution concentration used to collect $\mathrm{Br}$ and I species, vanadium pentoxide used as accelerator, sample mass, air flow rate through the reactor, temperature and reaction time were firstly studied.

\section{Solution used for analyte collection}

According to the literature, the F species (released from samples submitted to pyrohydrolysis) present in the water vapour can be just condensed and then collected. ${ }^{7,33,37}$ However, alkaline solutions are necessary for $\mathrm{Br}$ and I collection to avoid analyte losses and circumvent memory effects in their determination by ICP-MS. Therefore, solutions of tetramethylammonium hydroxide, ammonium hydroxide, and sodium carbonate/ sodium bicarbonate with concentrations up to $50 \mathrm{mmol} \mathrm{L}^{-1}$ were investigated for collecting the volatile $\mathrm{Br}$ and $\mathrm{I}$ species obtained from pyrohydrolysis. For comparison, the use of pure water was also evaluated. For these tests, the mass of sample + mass of $\mathrm{V}_{2} \mathrm{O}_{5}$ (sample $\mathrm{A}$ was used for these tests), air flow rate and reaction time were fixed at $1+3,300 \mathrm{~mL} \mathrm{~min}^{-1}$, and $10 \mathrm{~min}$, respectively. The results obtained showed that the best $\mathrm{Br}$ and I recoveries were achieved using $\mathrm{Na}_{2} \mathrm{CO}_{3} / \mathrm{NaHCO}_{3}$ solution to collect both elements. According to Figure 2, when the concentration of the $\mathrm{Na}_{2} \mathrm{CO}_{3} / \mathrm{NaHCO}_{3}$ solution was higher than $40 \mathrm{mmol} \mathrm{L}^{-1}$ the relative standard deviation for $\mathrm{Br}$ and
I decreased (RSD lower than $8 \%$ ). For $\mathrm{Br}$, recoveries close to $100 \%$ were obtained using $\mathrm{Na}_{2} \mathrm{CO}_{3} / \mathrm{NaHCO}_{3}$ solutions with concentration higher than $40 \mathrm{mmol} \mathrm{L}^{-1}$. For iodine, no significant difference was found (one-way - ANOVA, $\mathrm{P}<0.05$ ) for all absorbing solutions investigated. Thus, a $50 \mathrm{mmol} \mathrm{L} \mathrm{La}_{2} \mathrm{CO}_{3} / \mathrm{NaHCO}_{3}$ solution was used in subsequent experiments. It is important to point out that in case of $\mathrm{F}$ none absorbing solution is necessary. Quantitative recoveries of this element were also obtained using all absorbing solutions evaluated for $\mathrm{Br}$ and $\mathrm{I}$. In this sense, it is possible to suggest that if only $\mathrm{F}$ should be determined, pyrohydrolysis can be performed without using any absorbing solution. On the other hand, all analytes can be determined by using a $50 \mathrm{mmol} \mathrm{L}^{-1}$ $\mathrm{Na}_{2} \mathrm{CO}_{3} / \mathrm{NaHCO}_{3}$ solution.

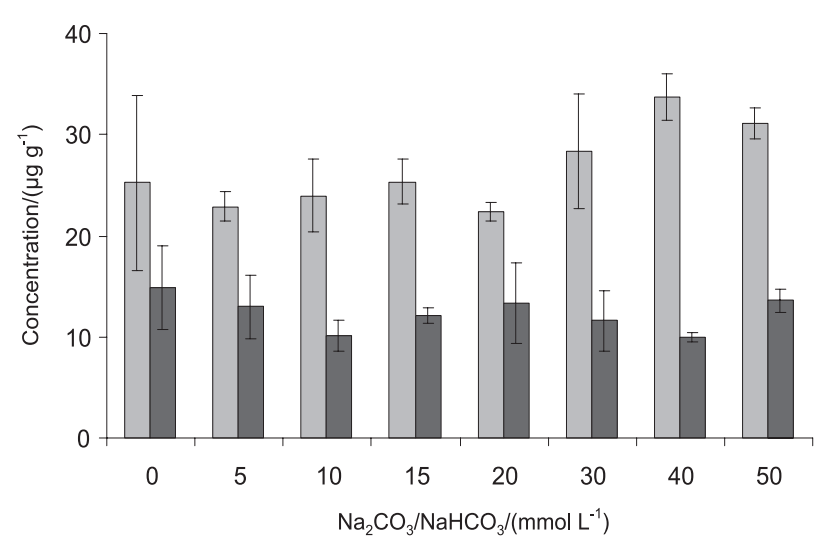

Figure 2. Influence of $\mathrm{Na}_{2} \mathrm{CO}_{3} / \mathrm{NaHCO}_{3}$ solution concentration used for collection of $\mathrm{Br}(\square)$ and $\mathrm{I}(\square)$; error bars are the standard deviations, $\mathrm{n}=5$.

Influence of accelerator on analyte recoveries

According to early applications of pyrohydrolysis for analytical purposes, the reaction is faster in the presence of certain oxides of $\mathrm{U}, \mathrm{W}, \mathrm{Al}$ and $\mathrm{V} .{ }^{37}$ In the present work, $\mathrm{V}_{2} \mathrm{O}_{5}$ was used due to its relatively low melting point (about $750{ }^{\circ} \mathrm{C}$ ) and suitability for different matrices. In order to evaluate the analytes release, $50 \mathrm{mg}$ of the sample A were mixed with aliquots up to $450 \mathrm{mg}$ of $\mathrm{V}_{2} \mathrm{O}_{5}$ (up to $1+9$ ). For these experiments, air flow rate, reaction time and $\mathrm{Na}_{2} \mathrm{CO}_{3} / \mathrm{NaHCO}_{3}$ concentration were $300 \mathrm{~mL} \mathrm{~min}^{-1}$, $10 \mathrm{~min}$ and $50 \mathrm{mmol} \mathrm{L}^{-1}$, respectively. It was observed that the precision improved with $\mathrm{V}_{2} \mathrm{O}_{5}$ amount increasing. Therefore, the sample $+\mathrm{V}_{2} \mathrm{O}_{5}$ mass ratio was kept in $1+5$ for subsequent experiments. These results are in agreement with results obtained in previous works. ${ }^{7,33}$ According to the literature, usually the use of an accelerator is necessary for halogens release from inorganic sample matrixes..$^{7,24,33,36}$ However, for other samples, like coal and petroleum coke, halogens are released without any auxiliary reagent. ${ }^{19,33,38}$ 


\section{Influence of air flow rate}

Air saturated with water vapour was employed for analyte transport from the pyrohydrolysis reactor to the condenser. For these experiments, the reaction time, sample mass $+\mathrm{V}_{2} \mathrm{O}_{5}$ mass proportion and $\mathrm{Na}_{2} \mathrm{CO}_{3} / \mathrm{NaHCO}_{3}$ concentration were set in $10 \mathrm{~min}, 1+5$, and $50 \mathrm{mmol} \mathrm{L}^{-1}$, respectively. Air flow rates from 100 to $600 \mathrm{~mL}^{-1}$ were evaluated and no significant difference was found for $\mathrm{F}$ and I (one-way - ANOVA, $\mathrm{P}<0.05$ ). In the case of $\mathrm{Br}$, the results obtained for air flow rate higher than $200 \mathrm{~mL} \mathrm{~min}^{-1}$ were statistically different (one-way - ANOVA, P < 0.05). The volume of water that passes through the pyrohydrolysis unit is dependent on the air flow rate. Thus, the water vapour volume increase with the air flow rate increasing. As a consequence a more diluted solution is produced, worsening the limit of detection (LOD). Therefore, the air flow rate selected was $200 \mathrm{~mL} \mathrm{~min}^{-1}$.

\section{Influence of temperature and reaction time}

The presence of $\mathrm{V}_{2} \mathrm{O}_{5}$, appropriate temperature and time of heating were mandatory for achieving good accuracy and precision. The temperature inside the reactor was varied from 700 to $1100{ }^{\circ} \mathrm{C}$ and it was verified that both precision and accuracy were better for $1000{ }^{\circ} \mathrm{C}$. The temperature was gradually increased until the fusion of the mixture sample + accelerator was completed, which occurred at $750{ }^{\circ} \mathrm{C}$ and after 2 min of heating at this temperature. Then, the temperature was increased up to $1000{ }^{\circ} \mathrm{C}$. For these experiments, the air flow rate, sample mass $+\mathrm{V}_{2} \mathrm{O}_{5}$ mass proportion and $\mathrm{Na}_{2} \mathrm{CO}_{3} / \mathrm{NaHCO}_{3}$ concentration were $200 \mathrm{~mL} \mathrm{~min}^{-1}, 1+5$ and $50 \mathrm{mmol} \mathrm{L}^{-1}$, respectively. The results obtained are shown in Figure 3. In case of $\mathrm{Br}$, no significant differences were found for reaction time up to 10 min (one-way - ANOVA, $\mathrm{P}<0.05$ ). For iodine, significant difference was found for reaction time up to 7.5 min (one-way - ANOVA, $\mathrm{P}<0.05$ ). Higher iodine concentration was found for $2.5 \mathrm{~min}$ of reaction but the precision was worst. For fluorine, no significant difference was found (one-way - ANOVA, $\mathrm{P}<0.05$ ) in all tests. Therefore, $10 \mathrm{~min}$ was established for further studies. It is important to mention that the pyrohydrolysis time must be enough for complete halogens release from sample matrix and to wash out the system in order to carry the analytes from reactor, capillaries and condenser to the collection flask. Therefore the time necessary for pyrohydrolysis can change according to sample matrix, analyte concentration and also the characteristics of the pyrohydrolysis system employed. ${ }^{17,19,32,37,39}$ In comparison with other sample preparation techniques ${ }^{10,20,25}$ for subsequent halogens determination, the pyrohydrolysis method proposed in this work can be considered relatively fast because up to 5 samples can be decomposed in $1 \mathrm{~h}$.

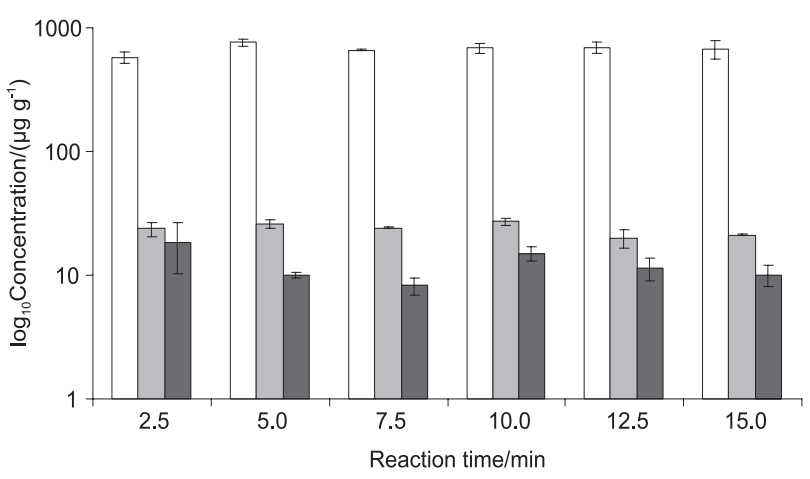

Figure 3. Influence of reaction time on analyte recovery. $\mathrm{F}(\square), \mathrm{Br}(\square)$ and I ( $\square$ ); error bars represents the standard deviation, $n=5$.

Sample analysis, precision and accuracy

The characteristics of the proposed pyrohydrolysis method, for sample preparation and determination of $\mathrm{F}, \mathrm{Br}$ and I are shown in Table 1.

Table 1. Characteristics of the developed pyrohydrolysis method for mineral supplement preparation prior to $\mathrm{F}, \mathrm{Br}$ and I determination

\begin{tabular}{ll}
\hline Parameter & Condition \\
\hline Air flow rate $/\left(\mathrm{mL} \mathrm{min}^{-1}\right)$ & 200 \\
Reactor temperature $/{ }^{\circ} \mathrm{C}$ & 1000 \\
Reaction time / min & 10 \\
Sample mass $/ \mathrm{mg}$ & $10-150$ \\
Sample mass $+\mathrm{V}_{2} \mathrm{O}_{5}$ mass proportion & $1+5$ \\
Sample throughput $/ \mathrm{h}^{-1}$ & 5 \\
Absorbing solution $\mathrm{Na}_{2} \mathrm{CO}_{3} / \mathrm{NaHCO} /\left(\mathrm{mmol} \mathrm{L}^{-1}\right)$ & $50(\mathrm{Br}$ and $\mathrm{I})$ \\
Relative standard deviation $\left(\mathrm{RSD}, \mathrm{n}^{2} 6\right) / \%$ & $\mathrm{~F}<4$ \\
& $\mathrm{Br}<4$ \\
Limit of quantification $(\mathrm{LOQ})^{\mathrm{a}} /\left(\mu \mathrm{gg} \mathrm{g}^{-1}\right)$ & $\mathrm{I}<11$ \\
& $\mathrm{~F}: 16$ \\
& $\mathrm{Br}: 0.3$ \\
\hline
\end{tabular}

aOQ calculated for $50 \mathrm{mg}$ of sample in $10 \mathrm{~mL}$ of solution for $\mathrm{F}$ (using ISE), and $50 \mathrm{mg}$ of sample in $15 \mathrm{~mL}$ of solution for $\mathrm{Br}$ and I (measured by ICP-MS).

The limit of quantification (LOQ) of F was calculated considering the lower Nernstian response of the ISE electrode $\left(0.15 \mathrm{mg} \mathrm{L}^{-1}\right.$ of $\left.\mathrm{F}^{-}\right)$, the sample amount $(50 \mathrm{mg})$ and the final dilution of the sample solution $(10 \mathrm{~mL})$. Although the sample mass employed ranged from 10 to $150 \mathrm{mg}$, it is possible to use higher amount of sample that improves the LOQ. The LOQs of Br and I were calculated according to the $3 \sigma$ criterion. The use of $50 \mathrm{mg}$ of sample 
and a final volume of $15 \mathrm{~mL}$ were also taken into account for the LOQs calculation. The LOQs of F, Br and I achieved by using ISE and ICP-MS were sufficiently low for these elements quantification in the analyzed samples.

Memory effects of $\mathrm{Br}$ and I in ICP-MS are usually observed when using pneumatic nebulization. However, the accuracy and precision achieved were good. This was mainly due to the use of alkaline solutions for calibration and as absorbing solution in pyrohydrolysis. The precision, expressed as the relative standard deviation (RSD) was better than $11 \%$ for all analytes. No certified reference materials with similar matrix of the analyzed samples were available. Therefore, the accuracy was checked by analyte recovery tests and analysis of certified phosphate rock and certified soil. Accuracy was better than $85 \%$, as shown in Table 2. It is important to mention that, although the matrix of certified reference materials used was not the same as the sample matrix, mineral supplements are prepared from phosphate rocks, which enable to suppose that this matrix is similar to sample matrix. The sample throughput is 5 samples per hour, which is good if one consider the difficulties related to the determination of $\mathrm{F}, \mathrm{Br}$ and $\mathrm{I}$ in mineral supplement. In addition, pyrohydrolysis is easy to be implemented and no toxic waste is generated.

Table 2. Recoveries of F, Br and I in spiked samples and in reference materials (mean \pm standard deviation, $n=6$ )

\begin{tabular}{lccc}
\hline \multirow{3}{*}{ Sample } & \multicolumn{3}{c}{ Recovery /\% } \\
\cline { 2 - 4 } & $\mathrm{F}^{\mathrm{a}}$ & $\mathrm{Br}^{\mathrm{b}}$ & $\mathrm{I}^{\mathrm{c}}$ \\
\hline $\mathrm{A}$ & $97 \pm 4$ & $88 \pm 2$ & $100 \pm 8$ \\
$\mathrm{~B}$ & $104 \pm 2$ & $90 \pm 3$ & $107 \pm 3$ \\
$\mathrm{C}$ & $100 \pm 4$ & $107 \pm 2$ & $99 \pm 6$ \\
D & $96 \pm 4$ & $95 \pm 3$ & $85 \pm 9$ \\
IPT-18 $^{\mathrm{d}}$ & $104 \pm 5$ & $\mathrm{nd}$ & $\mathrm{nd}$ \\
SRM 2711 $^{\mathrm{e}}$ & $\mathrm{nd}$ & $99 \pm 6$ & $90 \pm 7$ \\
\hline
\end{tabular}

nd = not determined; addition of F solution in order to obtain $10 \mathrm{mg} \mathrm{L}^{-1} \mathrm{~F}$ in the final solution after pyrohydrolysis; ${ }^{b}$ addition of Br solution in order to obtain $100 \mu \mathrm{g} \mathrm{L}^{-1} \mathrm{Br}$ in the final solution after pyrohydrolysis; ' addition of I solution in order to obtain 50, 100 and $150 \mu \mathrm{g} \mathrm{L}^{-1} \mathrm{I}$ in the final solution of samples $\mathrm{A}$ and $\mathrm{D}$, sample $\mathrm{B}$, and sample $\mathrm{C}$, respectively; ${ }^{\mathrm{d}}$ certified value: $1.35 \pm 0.13 \%$ of $\mathrm{F}^{-}$; einformed values: $5.0 \mu \mathrm{g} \mathrm{g}^{-1} \mathrm{Br}$ and $3.0 \mu \mathrm{g} \mathrm{g}^{-1} \mathrm{I}$.
After establishing the most important parameters of the developed method, it was applied to analysis of commercial mineral supplement samples used for animal nutrition. Fluorine determination in all samples was carried out using potentiometry with ISE, while $\mathrm{Br}$ and I were determined by ICP-MS. The results are shown in Table 3 where it can be observed that F concentrations in samples A, B, C, and D are relatively high (ranging from 600 to $1100 \mu \mathrm{g} \mathrm{g}^{-1}$ ). This is attributed either to the addition of $\mathrm{F}$ to the supplement formula or to the fact that $\mathrm{F}$ is naturally present in the phosphate rock used in formulation of the mineral supplements. ${ }^{40}$ Bromide concentrations found were similar for all samples (26 to $\left.31 \mu \mathrm{g} \mathrm{g}^{-1}\right)$. The mineral supplement producer did not inform the $\mathrm{Br}$ concentration but it was lower than the maximum concentration allowed. Iodide concentrations found in all samples were lower than the concentrations given by the producer (between 14 and $77 \mu \mathrm{g} \mathrm{g}^{-1}$ ), but it was in agreement with the legislation. ${ }^{4}$ In general, the concentrations of $\mathrm{F}$ and I determined after decomposition using pyrohydrolysis were different of those informed by the mineral supplements producer. However, it is not possible to suggest the reasons for the differences found. The producer does not inform which method was used to determine the concentrations of the investigated elements.

According to the Brazilian legislation, $\mathrm{Br}, \mathrm{F}$ and I concentrations found are in agreement and the mineral supplements could be given to animals.

In general, the determination of halogens in mineral supplement is challenging due to matrix complexity mainly the high concentration of salts, contamination and risk of analyte losses by volatilization during sample preparation (even using closed vessels). In this sense, the main drawback related to digestion methods is the high concentration of acid in the final solution. For halogens determination using ISE and ICP-MS techniques the $\mathrm{pH}$ of the solution must be 5.5 or higher. Fusion methods would increase matrix complexity due to the presence of additional electrolytes. The relatively high concentration of salts in the final solution can interfere in ICP-MS determinations. Pyrohydrolysis is more feasible because a diluted alkaline solution can be used for analytes collection and the analytes

Table 3. Determination of $\mathrm{F}, \mathrm{Br}$ and $\mathrm{I}$ in commercial mineral supplement (mean \pm standard deviation, $\mathrm{n}=6$ )

\begin{tabular}{|c|c|c|c|c|c|c|}
\hline \multirow{2}{*}{ Samples } & \multicolumn{3}{|c|}{ Informed values / $\left(\mu \mathrm{g} \mathrm{g}^{-1}\right)^{\mathrm{a}}$} & \multicolumn{3}{|c|}{ Determined values / $\left(\mu \mathrm{g} \mathrm{g}^{-1}\right)$} \\
\hline & $\mathrm{F}$ & $\mathrm{Br}$ & I & $\mathrm{F}$ & $\mathrm{Br}$ & I \\
\hline A & 757 & ni & 40 & $1077 \pm 79$ & $26.7 \pm 0.7$ & $14.7 \pm 1.7$ \\
\hline $\mathrm{B}$ & 900 & ni & 75 & $601 \pm 5$ & $26.9 \pm 0.9$ & $44.7 \pm 4.7$ \\
\hline $\mathrm{C}$ & 800 & ni & 77 & $900 \pm 51$ & $30.4 \pm 1.2$ & $10.5 \pm 0.8$ \\
\hline $\mathrm{D}$ & 800 & ni & 75 & $1049 \pm 102$ & $26.4 \pm 2.2$ & $57.6 \pm 4.3$ \\
\hline
\end{tabular}

ni = not informed values; ${ }^{\text {a }}$ values informed by the producer of the mineral supplement. 
are separated from the sample matrix. Additionally, the pyrohydrolysis apparatus is of low cost and the method can be easily implemented in laboratories. The LOQ and the accuracy are good.

\section{Conclusions}

The results obtained demonstrated that pyrohydrolysis is feasible for preparation of samples of mineral supplements used in animal nutrition prior to $\mathrm{F}, \mathrm{Br}$ and I determination. The main advantage is that the analytes are separated from sample matrix, avoiding interferences during the determination step, especially when ICP-MS is used. Only water (in case of fluorine) or a diluted alkaline solution is used for absorbing all analytes. The pyrohydrolysis method is fast, its implementation is relatively easy and of low cost. The method is attractive since concentrated acids and toxic reagents are not used. The use of $\mathrm{V}_{2} \mathrm{O}_{5}$ and $\mathrm{Na}_{2} \mathrm{CO}_{3} /$ $\mathrm{NaHCO}_{3}$ solution is inexpensive and without toxicity. Blank signals are low, which improves the LODs.

\section{Acknowledgments}

The authors are grateful to Conselho Nacional de Desenvolvimento Científico e Tecnológico (CNPq) and Coordenação de Aperfeiçoamento de Pessoal de Nível Superior (CAPES) for supporting this study.

\section{References}

1. Agency for Toxic Substances and Diseases Registry (ATSDR); Toxicological Profile for Fluorine, Hydrogen Fluoride and Fluorides, Atlanta, 2003.

2. Larsen, S.; Widdowso, A. E.; J. Soil Sci. 1971, 22, 210.

3. Agency for Toxic Substances and Disease Registry (ATSDR); Toxicological Profile for Bromoform and Dibromochloromethane, Atlanta, 2005.

4. National Research Council (NRC); Nutrient Requirements of Dairy Cattle, $7^{\text {th }}$ ed., Washington, 2001.

5. Olson, W. G.; Stevens, J. B.; Anderson, J.; Haggard, D. W.; J. Am. Vet. Assoc. 1984, 184, 179.

6. Wu, D.; Deng, H.; Wang, W.; Xiao, H.; Anal. Chim. Acta 2007, $601,183$.

7. Dressler, V. L.; Pozebon, D.; Flores, E. L. M.; Paniz, J. N. G.; Flores, E. M. M.; Anal. Chim. Acta 2002, 466, 117.

8. Moraes, D. P.; Pereira, J. S. F.; Diehl, L. O.; Mesko, M. F.; Dressler, V. L.; Paniz, J. N. G.; Knapp, G.; Flores, E. M. M.; Anal. Bioanal. Chem. 2010, 397, 563.

9. Pereira, J. S. F.; Diehl, L. O.; Duarte, F. A.; Santos, M. F. P.; Guimaraes, R. C. L.; Dressler, V. L.; Flores, E. M. M.; J. Chromatogr., A 2008, 1213, 249.
10. Flores, E. M. M.; Mesko, M. F.; Moraes, D. P.; Pereira, J. S. F.; Mello, P. A.; Barin, J. S.; Knapp, G.; Anal. Chem. 2008, 80, 1865.

11. Naozuka, J.; Veiga, M.; Oliveira, P. V.; Oliveira, E.; J. Anal. At. Spectrom. 2003, 18, 917.

12. Mesko, M. F.; Mello, P. A.; Bizzi, C. A.; Dressler, V. L.; Knapp, G.; Flores, E. M. M.; Anal. Bioanal. Chem. 2010, 398, 1125 .

13. Romaris-Hortas, V.; Moreda-Pineiro, A.; Bermejo-Barrera, P.; Talanta 2009, 79, 947.

14. Pereira,J.S.F.;Antes, F.G.; Diehl,L.O.; Knorr, C.L.; Mortari,S.R.; Dressler, V. L.; Flores, E. M. M.; J. Anal. At. Spectrom. 2010, $25,1268$.

15. Gelinas, Y.; Iyengar, G. V.; Barnes, R. M.; Fresenius J. Anal. Chem. 1998, 362, 483.

16. Flores, E. L. M.; Barin, J. S.; Flores, E. M. M.; Dressler, V. L.; Spectrochim. Acta, Part B 2007, 62, 918.

17. Conrad, V. B.; Brownlee, W. D.; Anal. Chem. 1988, 60, 365.

18. Wang, T. L.; Li, S. F. Y.; J. Chromatogr., A 1997, 781, 457.

19. Antes, F. G.; Duarte, F. A.; Flores, E. L. M.; Paniz, J. N. G.; Flores, E. M. M.; Dressler, V. L.; Quim. Nova 2010, 33, 1130.

20. Anazawa, K.; Tomiyasu, T.; Sakamoto, H.; Anal. Sci. 2001, 17, 217.

21. Pozebon, D.; Dressler, V. L.; Curtius, A. J.; Anal. Chim. Acta 2001, 438, 215.

22. Fecher, P. A.; Nagengast, A.; J. Anal. At. Spectrom. 1994, 9 , 1021.

23. Knapp, G.; Maichin, B.; Fecher, P.; Hasse, S.; Schramel, P.; Fresenius J. Anal. Chem. 1998, 362, 508.

24. Langenauer, M.; Krahenbuhl, U.; Furrer, V.; Wyttenbach, A.; Geostandard Newsletter 1992, 16, 41.

25. Souza, G. B.; Carrilho, E. N. V. M.; Oliveira, C. V.; Nogueira, A. R. A.; Nobrega, J. A.; Spectrochim. Acta, Part B 2002, 57, 2195.

26. Antes, F. G.; Duarte, F. A.; Mesko, M. F.; Nunes, M. A. G.; Pereira, V. A.; Müller, E. I.; Dressler, V. L.; Flores, E. M. M.; Talanta 2010, 83, 364

27. Duarte, F. A.; Pereira, J. S. F.; Barin, J. S.; Mesko, M. F.; Dressler, V. L.; Flores, E. M. M.; Knapp, G.; J. Anal. At. Spectrom. 2009, 24, 224.

28. Pereira, J. S. F.; Mello, P. A.; Duarte, F. A.; Santos, M. d. F. P.; Guimaraes, R. C. L.; Knapp, G.; Dressler, V. L.; Flores, E. M. M.; Energy Fuel 2009, 23, 6015.

29. Pereira, J. S. F.; Mello, P. A.; Moraes, D. P.; Duarte, F. A.; Dressler, V. L.; Knapp, G.; Flores, E. M. M.; Spectrochim. Acta, Part B 2009, 64, 554.

30. Filappi, A. R.; Prestes, D. S.; Antes, F. G.; Flores, E. L. M.; Dressler, V. L.; Flores, E. M. M.; Cecim, M.; Pesq. Vet. Bras. 2008, 28, 124

31. Bettinelli, M.; Spezia, S.; Minoia, C.; Ronchi, A.; At. Spectrosc. 2002, 23, 105 
32. Antes, F. G.; Duarte, F. A.; Paniz, J. N. G.; Santos, M. d. F. P.; Guimaraes, R. C. L.; Flores, E. M. M.; Dressler, V. L.; At. Spectrosc. 2008, 29, 157.

33. Dressler, V. L.; Pozebon, D.; Flores, E. L. M.; Paniz, J. N. G.; Flores, E. M. M.; J. Braz. Chem. Soc. 2003, 14, 334.

34. Bonifacie, M.; Jendrzejewski, N.; Agrinier, P.; Coleman, M.; Pineau, F.; Javoy, M.; Chem. Geol. 2007, 242, 187.

35. Fietzke, J.; Frische, M.; Hansteen, T. H.; Eisenhauer, A.; J. Anal. At. Spectrom. 2008, 23, 769.

36. Muramatsu, Y.; Takada, Y.; Matsuzaki, H.; Yoshida, S.; Quat. Geochronol. 2008, 3, 291.
37. Warf, J. C.; Cline, W. D.; Tevebaugh, R. D.; Anal. Chem. 1954, 26, 342.

38. Antes, F. G.; Santos, M. F. P.; Guimaraes, R. C. L.; Paniz, J. N. G.; Flores, E. M. M.; Dressler, V. L.; Anal. Methods 2011, 3, 288.

39. Doolan, K. J.; Anal. Chim. Acta 1987, 202, 61.

40. Marçal, W. S.; Gaste, L.; Carvalho, M. C.; Fortes, M. S.; PiolaJúnior, W.; Arq. Ciên. Vet. Zool. UNIPAR 2004, 7, 103.

Submitted: August 13, 2011

Published online: January 24, 2012 